\title{
Fast detection of Mycobacterium tuberculosis in culture-positive sputum samples by nitrate reductase activity
}

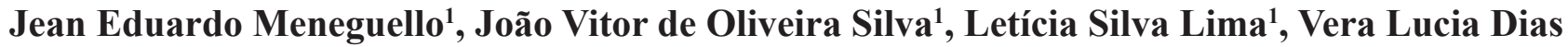

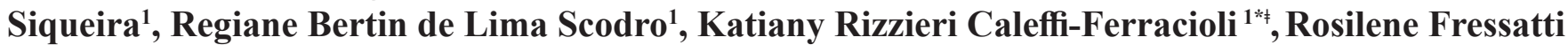 \\ Cardoso $^{1 *}$
}

\begin{abstract}
${ }^{1}$ Laboratory of Medical Bacteriology, Department of Clinical Analysis and Biomedicine, State University of Maringa, Parana, Brazil
\end{abstract}

\begin{abstract}
Microscopy and bacterial culture are the main tools in the diagnosis of tuberculosis. Since the slow growth of Mycobacterium tuberculosis impairs rapid diagnosis strategies, especially in countries where the latter are the only available resources, the ongoing development of new and inexpensive tools based on mycobacterial metabolism optimizing growth detection with preliminary identification is greatly welcome. When compared to the other species from the M. tuberculosis complex, M. tuberculosis is a strong nitrate reducer. Current assay compares the nitrate reductase activity of $M$. tuberculosis from pulmonary specimens cultivated in nitrate-supplemented media. Fifty-five sputum samples were decontaminated and inoculated in conventional (Middlebrook 7H9, Ogawa Kudoh-OK) and in nitratesupplemented media (Middlebrook 7H9-N, Ogawa Kudoh-N). An aliquot from the media directly reacted with Griess reagent (7H9-N and OK-N) every five days, or transferred to a nitrate substrate solution (7H9, OK). Nitrate to nitrite reduction was considered positive, revealed by the pink color, indicating bacterial growth. As reference method, the Mycobacteria Growth Indicator Tube (MGIT) was used for sensitivity calculations and statistical analysis. 7H9-N and OK-N assays proved to perform better in detecting M. tuberculosis than conventional assays ( $7 \mathrm{H} 9$ and $\mathrm{OK}$ ). Indeed, broth nitrate-supplemented medium (7H9-N) was comparable to MGIT to detect M. tuberculosis, except in growth detection time. Results show that 7H9-N may be used as an alternative tool particularly in low-income countries since it is a simple and cheap technique, and does not restrict diagnosis to single-source products.
\end{abstract}

Keywords: Tuberculosis. Mycobacteria/diagnosis/identification. Nitrate reductase.

\section{INTRODUCTION}

Tuberculosis (TB) mainly occurs by pulmonary infection caused by Mycobacterium tuberculosis. The disease has remained a global health threat due to multidrug resistance and to co-infection with the human immunodeficiency virus (HIV), aggravating its lethal potential. As a result, effective strategies and appropriate support are conducted to reverse the present TB status worldwide, focusing on diagnosis, prevention, treatment and research applied to this field (WHO, 2016).

The slow growth of the bacteria complex of $M$. tuberculosis is a liability since it delays rapid diagnosis

\footnotetext{
*Correspondence: K. R. Caleffi-Ferracioli. Laboratório de Bacteriologia Médica, Departamento de Análises Clínicas e Biomedicina, Universidade Estadual de Maringá. Avenida Colombo, 5790, 87020-900, Maringá, Paraná, Brasil. Tel: +55 44 3011-5375; Fax: +55 44 3011-4797. E-mail: katianyrcf@gmail.com

The authors collaborate equally in this study.
}

by conventional techniques, postponing the drug's susceptibility test (WHO, 2016). Although laboratory diagnosis of pulmonary TB is normally performed by microscopy and culture, the use of automated culture systems has recently been on the increase. For instance, BACTEC MGIT (Mycobacteria Growth Indicator Tube; Becton and Dickinson) is the most used automated system worldwide and kept in reference centers for TB diagnosis. Its growth detection mechanism is based on the monitoring of an oxygen-quenched fluorochrome depletion which triggers the growth detection process and makes the drug susceptibility profile faster (WHO, 2013).

On the other hand, in the case of countries with scanty resources, automation and molecular methods are still expensive and sometimes inaccessible (Adikaram, Perera, Wijesundera, 2012; Martin et al., 2011). Consequently, new and inexpensive tools for fast growth detection and identification of $M$. tuberculosis 
isolates from clinical specimens are of paramount importance. A fast TB diagnosis would optimize epidemiological actions and decrease the dissemination of M. tuberculosis strains, including drug-resistant ones, mainly in countries with high incidence of the disease (Adikaram, Perera, Wijesundera, 2012). Research for new alternatives and fast tools would also improve laboratories' independence for single-test commercial providers for TB diagnosis, particularly in low income countries (WHO, 2011, 2013).

M. tuberculosis nitrate reductase enzyme converts nitrate to nitrite using nitrate as a nitrogen source (Richardson et al., 2001). In addition, this bacterial feature has proved to be a suitable tool for Mycobacteria identification and has been employed in solid and broth media for a long time (Virtanen, 1960; Coban et al., 2014). During the last few years, this specific biochemical characteristic has been successfully applied in new approaches for fast TB diagnosis (Meyer, Sedlacek, Bange, 2003; Goh, Rastogi, 2010; WHO, 2011; Rojas-Ponce et al., 2013) and for drug susceptibility tests (Coban et al., 2014; Kumar et al., 2005). In fact, nitrate reductase activity has different behaviors and depends on the culture media used in the assay. Moreover, few reports have been published comparing time and limit of recovery of $M$. tuberculosis growth directly from sputum samples using solid and broth media. Current assay compares the employment of nitrate reductase activity in broth and solid media in the detection of $M$. tuberculosis growth from pulmonary specimens, in a routine laboratory.

\section{MATERIAL AND METHODS}

\section{Culture media}

Assays were conducted in Middlebrook (7H9) broth (Difco, Detroit MI USA) and Ogawa-Kudoh (OK) solid medium (Kudoh and Kudoh, 1974) without and with addition of sodium nitrate (7H9-N and OK-N). The $7 \mathrm{H} 9$ medium was prepared according to manufacturer's instructions, with $0.2 \%$ glycerol and supplemented with $10 \%$ Oleic acid, Albumin, Dextrose and Catalase OADC (Becton Dickinson Diagnostic Systems, Sparks, MD, USA), $0.1 \%$ casein and a lyophilized mixture of antimicrobials - MGIT PANTA (Becton Dickinson Diagnostic Systems, Sparks, MD, USA). The modified media, named 7H9-N and OK-N, were prepared as described above with the addition of $1 \mathrm{mg} / \mathrm{mL}$ of sodium nitrate (CAAL, São Paulo SP Brazil) in their formulation (Macedo et al., 2012).

\section{Limit of detection}

The limit of detection of each tested medium (7H9$\mathrm{N}, 7 \mathrm{H} 9$, OK and OK-N) was first determined by different concentrations of the reference strain $M$. tuberculosis $\mathrm{H}_{37} \mathrm{Rv}$ (ATCC 27294) $\left(3 \times 10^{8}, 1.5 \times 10^{4}, 1.5 \times 10^{3}, 1.5 \times 10^{2}\right.$ and $1.5 \times 10 \mathrm{CFU}$ ) and $M$. bovis AN5 at $3 \times 10^{8} \mathrm{CFU}$ (Figure 1). Each bacillus concentration was inoculated on $7 \mathrm{H} 9$ (3mL), 7H9-N (3 mL), OK, OK-N and incubated in normal atmosphere, at $35-37^{\circ} \mathrm{C}$. The same bacillary concentrations were inoculated in MGIT and incubated according to the manufacturer's instructions. MGIT was used as the reference method for Mycobacteria's growth detection.

Every five days, an aliquot of $300 \mu \mathrm{L}$ of $7 \mathrm{H} 9$ cultures was removed to a sterile tube containing $2 \mathrm{~mL}$ of sterile $22 \mathrm{mmol} / \mathrm{L}$ phosphate buffer and $10 \mathrm{mmol} / \mathrm{L}$ sodium nitrate and incubated at $35-37^{\circ} \mathrm{C}$ for 2 hours. Further, $225 \mu \mathrm{L}$ of freshly prepared Griess reagent (one part $50 \%$ hydrochloric acid, two parts $0.2 \%$ sulfanilamide and two parts $0.1 \%$ concentrated $N$-1-naphthylethylenediamine) were added. The light pink to red color turnaround (between $3+$ to $5+$ compared to the nitrate color standards) (Kent, Kubica, 1985; Adikaram, Perera, Wijesundera, 2012) indicated nitrate reduction and thus bacillus growth. Zinc powder was added to all primary negative sodium nitrate reduction assays to make sure that the reduction was not nitrogen-caused.

In the case of $7 \mathrm{H} 9-\mathrm{N}$, a $300 \mu \mathrm{L}$ aliquot from culture was removed every five days and $225 \mu \mathrm{L}$ of the Griess reagent were directly added for immediate nitrate reduction detection. Ziehl-Neelsen staining was carried out in $7 \mathrm{H} 9$ and 7H9-N nitrite positive cultures to confirm the acid-fast bacilli profile.

OK assay was daily monitored by visual inspection. The visualization of growth of M. tuberculosis complex typical colonies determined the time to perform the Griess reaction. Briefly, two spadesful of the culture were removed and added to $2 \mathrm{ml}$ of sterile $22 \mathrm{mmol} / \mathrm{L}$ phosphate buffer containing $10 \mathrm{mmol} / \mathrm{L}$ sodium nitrate and incubated at $35-37^{\circ} \mathrm{C}$ for 2 hours. Further, $225 \mu \mathrm{L}$ of Griess reagent were added to the assay and color change observed. For the OK-N reading, a slice of the medium containing typical colonies was transferred to another sterile tube and the sodium nitrate reduction was directly revealed by the addition of Griess reagent.

The M. bovis AN5 strain was used as control for weak nitrate reduction (nitrate color standards $<3+$ ).

All media were monitored for bacterial growth until the $40^{\text {th }}$ day, at $35-37^{\circ} \mathrm{C}$, for the confirmation of negative results. 


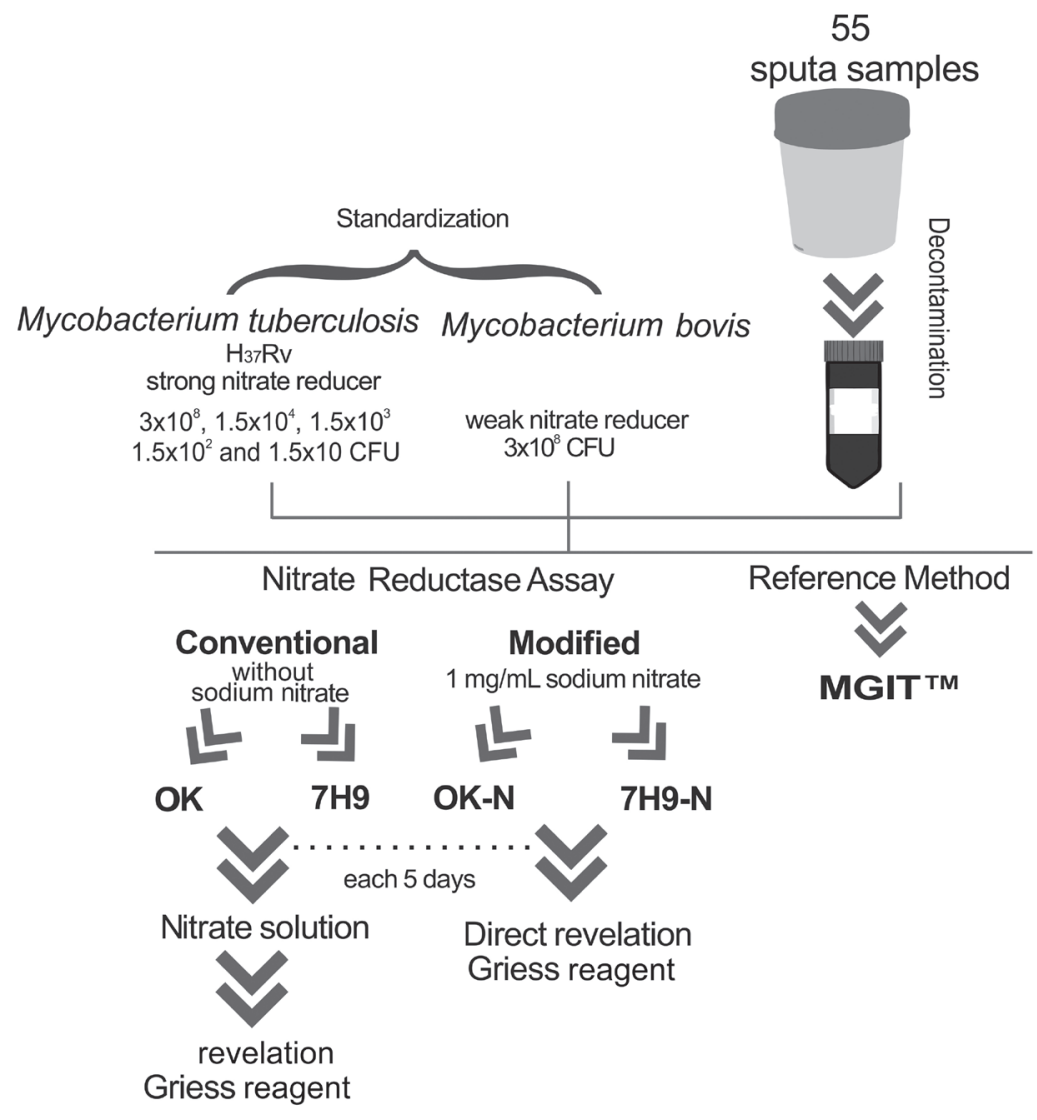

Interpretation:

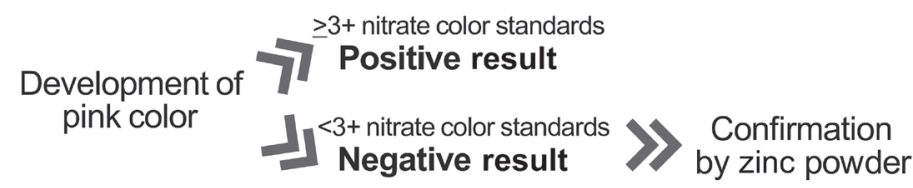

FIGURE 1 - Schematic representation of the procedure used for the standardization of Nitrate Reductase Assay. Limit of detection of assays and weak nitrate reduction pattern were determined by serial dilutions of Mycobacterium tuberculosis $\mathrm{H}_{37} \mathrm{Rv}$ and Mycobacterium bovis AN5 strains, respectively. Decontaminated sputa samples and reference strains were inoculated in media with and without nitrate (7H9, 7H9-N, OK, OK-N). The MGIT ${ }^{\mathrm{TM}}$ (Mycobacteria Growth Indicator Tube) (Becton Dickinson, USA) was used as a reference method for mycobacterial growth detection. Every five days, an aliquot of $300 \mu$ Lof 7H9-N media was directly read by adding $225 \mu \mathrm{L}$ of Griess reagent. In the case of $7 \mathrm{H} 9$ cultures, $300 \mu \mathrm{L}$ were inoculated in nitrate buffer and incubated for 2 hours till nitrite detection. In the case of solid media, a slice of medium was removed and reaction with Griess reagent was directly carried out for OK-N and indirectly in OK by adding the slice of medium in nitrate buffer solution to detect nitrate reduction. Development of a strong pink color indicates bacterial nitrate to nitrite reduction. CFU: colony forming units; OK: Ogawa Kudoh medium OK-N: Ogawa Kudoh medium supplemented with sodium nitrate; 7H9: Middlebrook 7H9; 7H9-N: Middlebrook supplemented with sodium nitrate.

\section{Sputa samples culture and presumptive identification of M. tuberculosis}

After protocol standardization, 55 randomly selected pulmonary specimens from patients attended by the Laboratorio de Ensino e Pesquisa em Análises Clínicas
(LEPAC), a reference center for TB diagnosis at the Universidade Estadual de Maringá, Maringá PR Brazil, were subjected to culture in 7H9-N, 7H9, OK and OK-N media and MGIT (Figure 1). Sputum samples were previously decontaminated according to MycoPrep MGIT Kit (Siddiqi, Rüsch-Gerdes, 2006), using NaOH-NALC 
procedure. Further, $180 \mu$ l of each sample were inoculated in 7H9 (3 ml), 7H9-N (3 ml), OK, OK-N and $500 \mu \mathrm{l}$ in MGIT. Manual assays were incubated in normal atmosphere at 35 $37^{\circ} \mathrm{C}$, and the MGIT assay was incubated in the automatic culture system, following manufacturer's instructions. MGIT was used as a reference method for Mycobacteria's growth detection. Similarly, all samples were monitored every five days as described for the standardization process. All acid-fast bacilli growth was identified by biochemical methods (Kent, Kubica, 1985).

\section{Ethical aspects}

Current study was approved by the Ethics Committee of the Universidade Estadual de Maringá, Maringá PR Brazil (Protocol n. 1.038. 941).

\section{Data analysis}

Data processing was performed with BioStata 5.3 software package (Brazil and USA). Data obtained on 7H9, 7H9-N, OK and OK-N were compared to MGIT results by $\mathrm{McNemar}$ test.

\section{RESULTS AND DISCUSSION}

M. tuberculosis is a strong nitrate reducer. Although this metabolic feature has been used for biochemical identification, recently it has also been employed as a useful growth marker. Other approaches based on nitrate reductase have been studied, such as drug susceptibility test (Kumar et al., 2005; Coban et al., 2011; Dixit et al., 2012) and analysis of the interaction between two or more anti-TB drugs. Despite the wide use of colorimetric methods, the limit of detection and bacterial recovery have not been determined (Il et al., 2013; Rojas-Ponce et al., 2013).

Other mycobacterial species also reduce nitrate, although they do not commonly cause diseases. Among non-tuberculous mycobacteria, fast growers (with the exception of $M$. chelonae) and some slow growers, such as M. kansasii, M. szulgai, M. flavescens and M. terrae, may reduce nitrate (Virtanen, 1960). In these cases, the colony's morphology and pigmentation aid in the identification, as these features are different from those presented by M. tuberculosis (Virtanen, 1960; Kent, Kubica, 1985). Current paper reports the experience with sodium nitrate incorporation in broth and solid culture media to optimize, simultaneously, growth detection and presumptive identification of $M$. tuberculosis isolates from pulmonary specimens.
During standardization of the assays, on the $10^{\text {th }}$ day of incubation, at $35-37^{\circ} \mathrm{C}$, positive sodium nitrate reduction by $M$. tuberculosis $\mathrm{H}_{37} \mathrm{Rv}$ was reported at $3 \times 10^{8}$, $1.5 \times 10^{4}$ and $1.5 \times 10^{3} \mathrm{CFU}$ inocula, and at $1.5 \times 10^{2} \mathrm{CFU}$ on the $20^{\text {th }}$ day. Visually detectable nitrite accumulation was observed in $7 \mathrm{H} 9$ only after the $20^{\text {th }}$ day of incubation. Colony formation was detected in OK and OK-N assays on the $10^{\text {th }}$ day of incubation with positive nitrate reduction observed at $3 \times 10^{8}$ and $1.5 \times 10^{4} \mathrm{CFU}$ inocula. In the case of $1.5 \times 10^{3}$ and $1.5 \times 10^{2} \mathrm{CFU}$ inocula, the sodium nitrate reduction in $\mathrm{OK}$ and $\mathrm{OK}-\mathrm{N}$ assays was reported only on the $15^{\text {th }}$ day of incubation. With regard to MGIT, control assay showed positive cultures at $1,6,7,8$ and 8 days for $3 \times 10^{8}, 1.5 \times 10^{4}, 1.5 \times 10^{3}, 1.5 \times 10^{2}, 1.5 \times 10 \mathrm{CFU}$ of $M$. tuberculosis $\mathrm{H}_{37} \mathrm{Rv}$, respectively. Based on these results, 7H9-N and OK-N assays proved to be more satisfactory and faster in detecting M. tuberculosis growth than $7 \mathrm{H} 9$ and OK assays. Results showed that increasing contact time between bacilli and substrate of nitrate reductase improved M. tuberculosis $\mathrm{H}_{37} \mathrm{Rv}$ growth detection by the culture medium supplementation.

No visual M. tuberculosis $\mathrm{H}_{37} \mathrm{Rv}$ growth in $\mathrm{OK}$ and in $\mathrm{OK}-\mathrm{N}$, or sodium nitrate reduction in $\mathrm{OK}$, OK$\mathrm{N}, 7 \mathrm{H} 9,7 \mathrm{H} 9-\mathrm{N}$ has been registered with $1.5 \times 10 \mathrm{CFU}$. Negative results in $7 \mathrm{H} 9-\mathrm{N}$ and $7 \mathrm{H} 9$ assays for $1.5 \times 10 \mathrm{CFU}$ inoculum were expected by the authors. According to the Middlebrook 7H9 manufacturer's instructions, the limit of viable bacilli recovery in clinical specimens is over $10^{2}$ to $3 \times 10^{2} \mathrm{CFU}$ (Power, Zimbro, 2009). Consequently, false negative results in nitrate reductase assay may be explained by the low concentration of bacilli in clinical specimens. This result was expected since the MGIT was used as the reference assay due to its higher sensitivity to metabolism detection by checking out hourly the rate of $\mathrm{O}_{2}$ consumption during bacillus growth (Rojas-Ponce et al., 2013). Modified assays 7H9-N and OK-N depend on the active metabolism of mycobacteria to reduce nitrate to nitrite or nitrogen. As a rule, the higher the bacilli concentration, the faster will be growth and nitrate reduction.

Since $M$. bovis AN5 strain showed weak nitrate reduction in all tested media, the difference is an important phenotypical feature to discriminate $M$. tuberculosis from $M$. bovis. In current study with pulmonary specimens, the sensitivity of 7H9-N and OK-N in detecting and having presumptive identification of $M$. tuberculosis growth was $88.9 \%$ (CI $63.9-98.1$ ) and $61.1 \%$ (CI $36.1-81.7$ ), respectively (Table I). MGIT was positive in $32.73 \%$ $(18 / 55)$ of clinical specimens, with an average detection time of 17.39 days (SD 7.94 days). Additionally, in our study, $30.9 \%(17 / 55)$ and $20 \%(11 / 55)$ of the samples 
were positive cultures with presumptive $M$. tuberculosis identification detected by $7 \mathrm{H} 9-\mathrm{N}$ and $\mathrm{OK}-\mathrm{N}$, respectively. From these positive cultures, $52.94 \%(9 / 17)$ and $63.64 \%$ (7/11) of growth, detection occurred from 15 to 25 days of incubation, respectively (Table I). No statistical difference between the performance of 7H9-N and MGIT has been observed $(\mathrm{p}>0.05)$. In contrast, there was a statistical difference $(\mathrm{p} \leq 0.05)$ when $7 \mathrm{H} 9$ and $\mathrm{OK}$ were compared to MGIT. Therefore, in low resource laboratories, these two assays could be auxiliary tools for a fast TB diagnosis.

The nitrate-supplemented Middlebrook broth (7H9$\mathrm{N})$ proved to be better for the detection of bacillus growth in clinical specimens. The 7H9-N assay revealed an easy and fast evidence of the presumptive M. tuberculosis growth by the strong reduction of nitrate into nitrite when compared to the solid media, OK and OK-N. Our results corroborate those by Rageade et al. (2014). The difference between solid and broth media is well explained due to favorable growth in broth medium and the need to visualize colonies in solid form to perform nitrate reductase reaction. Nonetheless, OK-N or OK allows the visual observation of typical colony morphology and pigment production. The OK medium was chosen for sodium nitrate supplementation in current assay due to its buffered formulation and to the easy and fast sputum decontamination protocol, by which specimen cultures may be feasible in any clinical laboratory for implementing TB diagnosis.

Similar to the standardization process and rather than $7 \mathrm{H} 9$ with clinical specimens, $7 \mathrm{H} 9-\mathrm{N}$ detected bacillus growth faster. The performance is statistically comparable to MGIT ( $p>0.05$ ). Further, 7H9-N has an advantage over MGIT by allowing the preliminary identification of the bacillus simultaneously with growth detection. The addition of sodium nitrate in the medium caused fast bacillus phenotypic identification without impairing its growth, corroborating studies by (Meyer et al., 2003; Goh, Rastogi, 2010). Macedo et al. (2012) reported that, when sodium and potassium nitrate were compared, the two were metabolized as substrate.

The bacillus identification, based on the nitrate reductase reaction, requires attention due to clinical specimen contamination. Since nitrate reductase enzymes occur in Klebsiella oxytoca, Pseudomonas aeruginosa, Salmonella typhimurium and other bacteria, the strong alkali decontamination process carried out in clinical specimens, as described by Kudoh (Kudoh, Kudoh, 1974), may minimize false positive results. Therefore, growth time, acid fastness and cord factor observed by ZiehlNeelsen staining may determine the fast and presumptive presence of M. tuberculosis.

\section{CONCLUSION}

The culture medium sodium nitrate supplementation, similar to 7H9-N, was an inexpensive and fast alternative method to detect $M$. tuberculosis growth through simultaneous biochemical presumptive identification when automated culture systems are not available for TB diagnosis. The 7H9-N performance in M. tuberculosis

TABLE I - Comparison of media without (7H9 and OK) and supplemented by sodium nitrate (7H9-N and OK-N) with the Mycobacteria Growth Indicator Tube (MGIT) for Mycobacterium tuberculosis growth detection and fast presumptive identification in a 40-day culture

\begin{tabular}{|c|c|c|c|c|c|c|c|c|c|c|}
\hline \multirow{2}{*}{ Assay } & \multicolumn{4}{|c|}{$\begin{array}{l}\text { Growth detection and presumptive identification of } \\
\text { Mycobacterium tuberculosis }\end{array}$} & \multicolumn{3}{|c|}{$\begin{array}{c}\text { Days for Mycobacterium tuberculosis } \\
\text { growth detection (\%) } \\
\end{array}$} & \multirow{2}{*}{$\begin{array}{l}\text { Sensitivity } \\
(\%)\end{array}$} & \multirow{2}{*}{$\begin{array}{c}\text { Positive } \\
\text { Predictive } \\
\text { value } \\
(\%)\end{array}$} & \multirow{2}{*}{$\begin{array}{c}\text { Negative } \\
\text { Predictive } \\
\text { value } \\
(\%)\end{array}$} \\
\hline & $\begin{array}{c}\text { True } \\
\text { positive (n) }\end{array}$ & $\begin{array}{c}\text { True } \\
\text { negative (n) }\end{array}$ & $\begin{array}{c}\text { False } \\
\text { positive (n) }\end{array}$ & $\begin{array}{c}\text { False } \\
\text { negative (n) }\end{array}$ & $0-10$ & $15-25$ & $30-40$ & & & \\
\hline MGIT $^{a}$ & 18 & 37 & - & - & 27.78 & 61.11 & 11.11 & - & - & - \\
\hline $7 \mathrm{H} 9$ & 1 & 37 & 0 & $17^{\mathrm{b}}$ & - & - & 5.55 & $\begin{array}{c}5.6 \\
(0.3-29.4)\end{array}$ & $\begin{array}{c}100 \\
(5.5-100)\end{array}$ & $\begin{array}{c}68.5 \\
(54.3-80.1)\end{array}$ \\
\hline OK & 11 & 37 & 0 & $7^{\mathrm{b}}$ & - & 18.18 & 81.82 & $\begin{array}{c}61.1 \\
(36.1-81.7)\end{array}$ & $\begin{array}{c}1 \\
(67.9-100)\end{array}$ & $\begin{array}{c}84.1 \\
(69.3-92.8)\end{array}$ \\
\hline OK-N & 11 & 37 & 0 & $7^{\mathrm{b}}$ & - & 63.64 & 36.36 & $\begin{array}{c}61.1 \\
(36.1-81.7)\end{array}$ & $\begin{array}{c}2 \\
(67.9-100)\end{array}$ & $\begin{array}{c}84.1 \\
(69.3-92.8)\end{array}$ \\
\hline
\end{tabular}

a: MGIT PANTA (Becton Dickinson Diagnostic Systems, Sparks, MD, USA) - assay used as reference; 7H9: Middlebrook 7H9 broth (Difco, Detroit, MI, USA); OK: Ogawa-Kudoh solid medium according to Kudoh and Kudoh (1974); 7H9-N: Middlebrook 7H9 added of sodium nitrate; OK-N: Ogawa-Kudoh solid medium added of sodium nitrate; ${ }^{\text {b }}$ : Negative assay until $40^{\text {th }}$ days of incubation at $35 \pm 2{ }^{\circ} \mathrm{C}$; ${ }^{\text {c }}$ Positive assay by non acid fast bacilli (AFB). 
growth detection from sputum samples was comparable to MGIT, except for growth detection time. Results show that the nitrate reductase assay may be an auxiliary tool for early TB diagnosis, particularly in low-income countries where laboratories have limited resources, providing independence of single-test commercial providers.

\section{ACKNOWLEDGMENTS}

The authors would like to thank the Medical Bacteriology Division of the Laboratório de Ensino e Pesquisa em Análises Clínicas (LEPAC), Universidade Estadual de Maringá, Maringá PR Brazil, for their collaboration in the study.

\section{CONFLICT OF INTEREST}

There is no conflict of interest.

\section{ETHICAL APPROVAL}

Formal consent is not required for this type of study.

\section{REFERENCES}

Adikaram CP, Perera J, Wijesundera SS. The manual mycobacteria growth indicator tube and the nitrate reductase assay for the rapid detection of rifampicin resistance of M. tuberculosis in low resource settings. BMC Infect Dis. 2012;12:326.

Coban AY, Cayci YT, Deveci A, Akgunes A, Uzun M, Durupinar B. A rapid detection of multidrug-resistant Mycobacterium tuberculosis by a nitrate reductase assay on blood agar. Mem Inst Oswaldo Cruz. 2011;106(3):378-80.

Coban AY, Deveci A, Sunter AT, Martin A. nitrate reductase assay for rapid detection of isoniazid, rifampin, ethambutol, and streptomycin resistance in Mycobacterium tuberculosis: a systematic review and meta-analysis. J Clin Microbiol. 2014;52(1):15-9.

Dixit P, Singh U, Sharma P, Jain A. Evaluation of nitrate reduction assay, resazurin microtiter assay and microscopic observation drug susceptibility assay for first line antitubercular drug susceptibility testing of clinical isolates of M. tuberculosis. J Microbiol Methods. 2012;88(1):122-6.
Goh KS, Rastogi N. Simple and rapid method for detection of nitrate reductase activity of Mycobacterium tuberculosis and Mycobacterium canettii grown in the Bactec MGIT960 system. J Microbiol Methods. 2010;81(2):208-10.

Il YB, Orikiriza P, Rojas-Ponce G, Riera-Montes M, Atwine D, Nansumba M, et al. Use of colorimetric culture methods for detection of Mycobacterium tuberculosis complex isolates from sputum samples in resource-limited settings. J Clin Microbiol. 2013;51(7):2273-9.

Kent PT, Kubica GP. Public health mycobacteriology: a guide for the level III laboratory. Atlanta, Ga: Department of Health and Human Services; 1985. p. 96-103.

Kudoh S, Kudoh T. A simple technique for culturing tubercle bacilli. Bull World Heal Organ. 1974;51(1):71-82.

Kumar M, Khan IA, Verma V, Kalyan N, Qazi GN. Rapid, inexpensive MIC determination of Mycobacterium tuberculosis isolates by using microplate nitrate reductase assay. Diagn Microbiol Infect Dis. 2005;53(2):121-4.

Macedo MB, Von Groll A, Fissette K, Palomino JC, Almeida da Silva PE, Martin A. Nitrate reductase assay using sodium nitrate for rapid detection of multidrug resistant tuberculosis. Brazilian J Microbiol. 2012;43(3):981-3.

Martin A, Paasch F, Docx S, Fissette K, Imperiale B, Ribon $\mathrm{W}$, et al. Multicentre laboratory validation of the colorimetric redox indicator (CRI) assay for the rapid detection of extensively drug-resistant (XDR) Mycobacterium tuberculosis. J Antimicrob Chemother. 2011;66(4):827-33.

Meyer A, Sedlacek L, Bange FC. Rapid testing for nitrate reductase activity of Mycobacterium tuberculosis grown in an automated culture system. Eur J Clin Microbiol Infect Dis. 2003;22(7):444-6.

Power D, Zimbro M. Difco \& BBL manual: manual of microbiological culture media [Internet]. Mary Jo Zimbro, B.S. M (ASCP), David A. Power PD, Sharon M. Miller, B.S. M (ASCP), George E. Wilson, MBA, B.S., MT (ASCP) Julie A. Johnson BA, editors. Citeseer. Becton, Dickinson and Company 7 Loveton Circle P.O. Box 999 Sparks, Maryland 21152; 2009. [cited 2017 August 08]. Avaiable in: http://www.bd.com/ resource. aspx ?IDX $=9572$. 
Fast detection of Mycobacterium tuberculosis in culture-positive sputum samples by nitrate reductase activity

Rageade F, Picot N, Blanc-Michaud A, Chatellier S, Mirande C, Fortin E, et al. Performance of solid and liquid culture media for the detection of Mycobacterium tuberculosis in clinical materials: meta-analysis of recent studies. Eur J Clin Microbiol Infect Dis. 2014;33(6):867-70.

Richardson DJ, Berks BC, Russell DA, Spiro undefined S, Taylor CJ. Functional, biochemical and genetic diversity of prokaryotic nitrate reductases. Cell Mol Life Sci. 2001;58(2):165-78.

Rojas-Ponce G, Rachow A, Guerra H, Mapamba D, Joseph J, Mlundi R, et al. A continuously monitored colorimetric method for detection of Mycobacterium tuberculosis complex in sputum. Int J Tuberc Lung Dis. 2013;17(12):1607-12.

Siddiqi SH, Rüsch-Gerdes S. MGIT Procedure Manual for BACTEC ${ }^{\text {TM }}$ MGIT 960 ${ }^{\mathrm{TM}}$ TB System. Geneva: FIND; 2006. $89 \mathrm{p}$.
Virtanen S. A study of nitrate reduction by mycobacteria. The use of the nitrate reduction test in the identification of mycobacteria. Acta Tuberc Scand Suppl. 1960;48:1-119.

World Health Organization. WHO. Strategic and Technical Advisory Group for Tuberculosis, Report of 13th meeting. Geneva, Switzerland: World Health Organization; 2013. 34 p.

World Health Organization. WHO. Noncommercial culture and drug-susceptibility testing methods for screening patients at risk for multidrug-resistant tuberculosis: policy statement. Geneva, Switzerland: World Health Organization; 2011. 12 p.

World Health Organization. WHO. Global Tuberculosis Report. Geneva, Switzerland: World Health Organization; 2016. 201 p.

Received for publication on $20^{\text {th }}$ September 2016 Accepted for publication on $17^{\text {th }}$ July 2017 


\section{Erratum}

In the article "Fast detection of Mycobacterium tuberculosis in culture-positive sputum samples by nitrate reductase activity", number doi: 10.1590/s2175-97902018000100014, published in the Brazilian Journal of Pharmaceutical Sciences, vol54, n1:

\section{Where it was written:}

João Vitor Oliveira

\section{Should read:}

João Vitor de Oliveira Silva 